\title{
LXXVI. Observations on the isothermal lines on the Northwest Coast of America, as deduced from the results in the two preceding articles
}

\section{Sir David Brewster LL.D. F.R.S.}

To cite this article: Sir David Brewster LL.D. F.R.S. (1832) LXXVI. Observations on the isothermal lines on the Northwest Coast of America, as deduced from the results in the two preceding articles, Philosophical Magazine Series 3, 1:6, 431-432, DOI: 10.1080/14786443208647934

To link to this article: http://dx.doi.org/10.1080/14786443208647934

曲 Published online: 01 Jun 2009.

Submit your article to this journal

Џll Article views: 2

Q View related articles $\sqsubset$ 
Sir D. Brewster on certain Isothermal Lines in America. 431

TableIII.-Showing the State of the Winds observed thrice a day.

During the past year there were,

\begin{tabular}{ll|rl|rl|rl}
92 & North winds & 85 & West & 170 & South & 23 & East \\
49 & NNW & 45 & WSW & 34 & SSE & 6 & ENE \\
59 & NW & 106 & SW & 49 & SE & 42 & NE \\
32 & WNW & 41 & SSW & 15 & ESE & 21 & NNE.
\end{tabular}

Hence we see that the prevailing winds are those of the south and the south-roest.

LXXVI. Observations on the Isothermal Lines on the Northwest Coast of America, as deduced from the Results in the two preceding Articles. By Sir David Brewster, LL.D. F.R.S. \& c.

I $N$ determining the inflexions of the isothermal lines round the pole of maximum cold in the Arctic regions to the North of America, I employed the valuable observations of Mr. Scoresby; a long and valuable series of observations made on the west coast of Greenland, and communicated to me by Sir Charles Giesecke; together with observations made in Iceland, and in different parts of Canada. I sought in vain, however, for measures of mean temperatures in those parts of the Arctic regions which are placed in a meridian nearly opposite to our own; and it is therefore a source of great satisfaction to me to have received from $M$. Kupffer the valuable observations contained in the two preceding papers. These observations indeed have been yet made for too short a period to give us a very accurate measure of mean temperature; but the approximate results which they afford will be of some use, till we obtain a larger series.

In order to compare the observed mean temperatures of Jloulouk and Sitka with those calculated from the formula

$$
\text { Mean temperature }=\left(86^{\circ} \cdot 3 \sin \mathrm{D}\right)-3 \frac{1}{2} \text {, }
$$

$D$ being the distance of the place of observation from the North American pole of maximum cold, which is situated in north latitude $80^{\circ}$, and west longitude $100^{\circ}$.

Professor Kupffer has not given us the longitude and latitude of Jloulouk and Sitka. The position of Ounalachka, however, according to the observations of English navigators, is between $168^{\circ} 4.0^{\prime}$ and $168^{\circ}$ of west longitude, and between $53^{\circ} 45^{\prime}$ and $54^{\circ}$ of north latitude. We shall take, there- 
fore, the position of Jloulouk at $168^{\circ} 20^{\prime}$ west longitude, and $53^{\circ} 53^{\prime}$ of north latitude; and from these data we shall find ............... D $=33^{\circ} 23^{\prime}$

And the calculated mean temperature of Jloulouk $43^{\circ} \cdot 980$ Observed mean temperature . . . . . . . 40.325

$$
\text { Difference ... } \overline{+3 \cdot 655}
$$

This difference between the formula and observation is much greater than usual; but we shall presently see that it must arise either from the observations not affording a correct mean, or from the temperature of the place being affected by local causes.

I presume that Sitka is the same place as the Isle of Sitka, iu the Great Northern Ocean, where Dr. Erman made his magnetical observations. The following extract from Dr. Erman's table, given in his letter to the academician M.Wisniewsky, and published in the Bulletin Scientifique, will enable us to approximate to the position of Sitka.

North Lat. West Long. Nov. 4. In the Great Northern Ocean $56^{\circ} 54^{\prime} \cdot 20 \quad 223^{\circ} 53^{\prime} \cdot 20$ - 12. At the Isle of Sitka . . . . $57 \quad 3.12$

- 20. In the Great Northern Ocean 54 26.50 $22122 \cdot 80$ As Dr. Erman has omitted to give the longitude of Sitka, we may infer from the preceding table that it cannot be far from $222^{\circ}$.

Hence we obtain $\mathrm{D}=25^{\circ} 38^{\prime}$, and

The calculated mean temperature of Sitka .. $33^{\circ} \cdot 84$ Fahr. Observed mean temperature ........ 45.05

$$
\text { Difference...... } \overline{-11 \cdot 21}
$$

This difference is so extraordinary, that we must either have mistaken the locality of Sitka, or there must be some singular source of heat in the island, or some inexplicable error in the observations. The reader will observe, that the difference is now -, whereas it was + in the case of Jloulouk.

Without taking the formula as our guide, we have only to consider that Jloulouk, in latitude $53^{\circ} 53^{\prime}$, has only a temperature of $40^{\circ}$; while Sitka, in latitude $57^{\circ} 3^{\prime}$, has a temperature of $45^{\circ}$ ! in order to be convinced that the formula will not be found to be in fault. We must wait, therefore, for other observations from these regions before we can explain the cause of this singular discrepancy. 